\title{
Aerosol Assisted Atmospheric Pressure Chemical Vapor Deposition of Silicon Thin Films using Liquid Cyclic Hydrosilanes
}

\author{
Srinivasan Guruvenket ${ }^{\dagger,}$, Justin M. Hoey ${ }^{\dagger}$, Kenneth J. Anderson ${ }^{\dagger}$, Matthew T. \\ Frohlich $^{\dagger}$, Robert A. Sailer ${ }^{\dagger}$ and Philip. Boudjouk ${ }^{£}$ \\ ${ }^{\dagger}$ Center for Nanoscale Science and Engineering, 1715 NDSU Research Park Drive N, North \\ Dakota State University, Fargo, North Dakota 58102, USA. \\ ${ }^{£}$ Department of Chemistry and Biochemistry, Ladd-Dunbar Hall, North Dakota State University, \\ Fargo, North Dakota 58102, USA.
}

\begin{abstract}
Silicon ( $\mathrm{Si}$ ) thin films were produced using an aerosol assisted atmospheric pressure chemical vapor deposition technique with liquid hydrosilane precursors cyclopentasilane $\left(\mathrm{CPS}, \mathrm{Si}_{5} \mathrm{H}_{10}\right)$ and cyclohexasilane (CHS, $\mathrm{Si}_{6} \mathrm{H}_{12}$ ). Thin films were deposited at temperatures between 300-500 ${ }^{\circ} \mathrm{C}$, with maximum observed deposition rates of 55 and $47 \mathrm{~nm} / \mathrm{s}$ for CPS and CHS, respectively, at $500{ }^{\circ} \mathrm{C}$. Atomic force microscopic analysis of the films depicts smooth surfaces with roughness of 4-8 $\mathrm{nm}$. Raman spectroscopic analysis indicates that the Si films deposited at 300 ${ }^{\circ} \mathrm{C}$ and $350{ }^{\circ} \mathrm{C}$ consist of a hydrogenated amorphous $\mathrm{Si}(\mathrm{a}-\mathrm{Si}: \mathrm{H})$ phase while the films deposited at 400,450 , and $500{ }^{\circ} \mathrm{C}$ are comprised predominantly of a hydrogenated nanocrystalline Si (nc$\mathrm{Si}: \mathrm{H})$ phase. The wide optical bandgaps of $2-2.28 \mathrm{eV}$ for films deposited at $350-400{ }^{\circ} \mathrm{C}$ and $1.7-$ $1.8 \mathrm{eV}$ for those deposited at $450-500{ }^{\circ} \mathrm{C}$ support the Raman data and depict a transition from aSi:H to nc-Si:H. Films possessing the highest photosensitivity of $10^{2}-10^{3}$ under AM $1.5 \mathrm{G}$ illumination. Based on the growth model developed for other silanes, we present a possible mechanism that governs the film growth using CPS and CHS.
\end{abstract}

Keywords: Cyclopentasilane; Cyclohexasilane; Liquid silane; High-rate deposition, Aerosol assisted CVD; Silicon thin films

\section{Corresponding author}

e-mail: guruvenket.srinivasan@ndsu.edu, guruvenkat @gmail.com

Phone: +1(701)234 5299 


\section{Introduction}

Silicon ( $\mathrm{Si}$ ) is the most widely used semiconducting material due to its availability, ease of processing, low environmentally impact and low cost. Si thin films comprise a wide range of properties which can be engineered by controlling the growth conditions. Si films are usually grown via a bottom-up approach such as chemical vapor deposition (CVD). In CVD, a gaseous silane precursor is thermally decomposed to form $\mathrm{Si}$ thin films. Due to the high temperatures employed, CVD effectively restricts the available substrates to those stable at high temperatures. Integration of plasma with CVD (PECVD) enables the use of temperature sensitive substrates but at the cost of deposition rate and efficiency. State-of-the-art PECVD processes being used in $\mathrm{Si}$ thin film solar cell fabrication utilize only $\sim 15 \%$ [1] of the precursor $\left(\right.$ monosilane, $\left.\mathrm{SiH}_{4}\right)$ making the process more expensive than the emerging chalcogenide and chalcopyrite based solar cells [2]. Thin film fabrication costs are further increased due to the pyrophoric nature of the silane gas and low-pressure requirements.

Alternatively, using higher order silanes, via CVD and PECVD resulted in incremental benefits to deposition temperature, rate and efficiency at the lab-scale. This approach has not yet been scaled to manufacturing levels, possibly due to the inconsistency in silane vaporization [38]. For an example, Chung et al., studied Si film deposition using neopentasilane (NPS) via lowpressure CVD, and found enhanced growth rates [4]. However, significant modification to the standard gas delivery methods for the transportation of the precursor to the CVD reactor was necessary [9].

Solution based processing utilizing liquid hydrosilanes allows for ambient pressure growth of Si thin films [10], but the challenges associated with scale-up, alloying, degenerate doping of Si and fabricating multi-layered device structures remain unaddressed [11]. These challenges are being investigated by several groups, including ours [10]. However, a scalable method producing comparable results to state-of-the-art gaseous silane deposition routes is currently unavailable.

One benefit of liquid silanes is in the accelerated deposition rate which has been shown to increase with higher order hydrosilanes (increasing trend from monosilane to NPS), but a continuous and large scale process still remains critical for the incorporation of liquid silanes into manufacturing-scale device fabrication. In this research article, we present results using aerosol 
assisted atmospheric pressure chemical vapor deposition (AA-APCVD) for the synthesis of $\mathrm{Si}$ thin films with cyclopentasilane (CPS, $\left.\mathrm{Si}_{5} \mathrm{H}_{10}\right)$ and cyclohexasilane $\left(\mathrm{CHS}, \mathrm{Si}_{6} \mathrm{H}_{12}\right)$ as the silicon precursors.

\section{Materials and methods}

\subsection{Materials}

A solution of 10 vol. \% CPS in cyclooctane (provided by Nissan Chemical, Japan) and 10 vol. \% CHS (synthesized in-house) in cyclooctane ( $\geq 99 \%$ purity, Sigma Aldrich) were used as precursors. The as-received cyclooctane was degassed with nitrogen, distilled, and dried with molecular sieves. The CHS solution was prepared in a nitrogen filled glove box. A detailed description of the synthesis and purification schemes of CHS can be found elsewhere [12] [13].

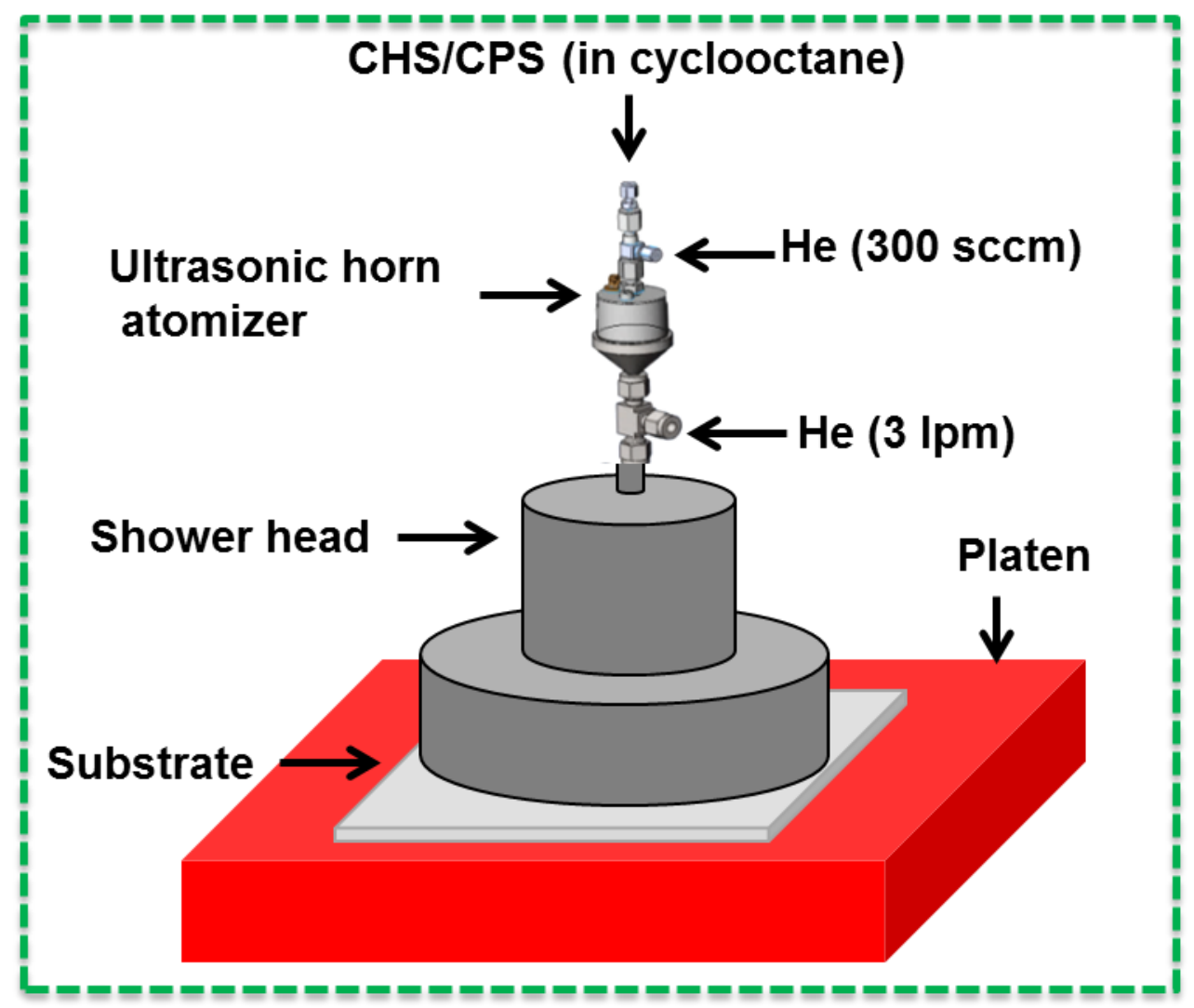

Fig. 1. Schematic representation of AA-APCVD (located in nitrogen filled glove box where $\mathrm{H}_{2} \mathrm{O}$ and $\mathrm{O}_{2}$ are $<1$ ppm). 


\subsection{Silicon thin film deposition}

A schematic representation of the AA-APCVD is shown in Fig. 1. The precursors are controllably injected using a syringe pump into an ultrasonic horn atomizer (Sono-Tek Inc. Milton, NY) operating at $120 \mathrm{kHz}$. Helium (He) at a flow rate of $300 \mathrm{sccm}$ directed through the atomizer which carries the aerosol mist into a circular showerhead. An additional $3 \mathrm{lpm}$ of He is added to vaporize and dilute the aerosol and deliver it to the substrate surface. The platen can be heated to a maximum of $500{ }^{\circ} \mathrm{C}$ and is fixed to an $\mathrm{X}-\mathrm{Y}$ stage, allowing for controllable movement of the substrate beneath the showerhead. The entire apparatus (AA-APCVD) is located inside an inert atmosphere $\left(\mathrm{N}_{2},<1 \mathrm{ppm} \mathrm{O}_{2} / \mathrm{H}_{2} \mathrm{O}\right)$ glove box to preclude exposure of the liquid silanes and the deposited Si thin films to ambient oxygen and water vapor. Depositions are on 1" x 1" $\mathrm{SiO}_{2}$ (fused silica/quartz) substrates that were RCA cleaned [14], and coated with a $200 \mathrm{~nm}$ thick a-SiO 2 (via PECVD) as a diffusion barrier for any potential contamination from the substrate. The substrate temperatures were maintained at $300-500{ }^{\circ} \mathrm{C}$. Distance between the showerhead and the substrate was 2-3 $\mathrm{mm}$. All other parameters are kept constant including CPS/CHS solution flow rate (1.2 $\mathrm{ml} /$ hour).

\subsection{Thin film characterization}

Film thickness was determined by measuring the step height of $200 \mu \mathrm{m}$ wide, laser ablated trenches formed in the Si, using a KLA Tencor contact profiler. Spectroscopic ellipsometry (J.A. Woollam VASE) analysis was used to validate the thickness data obtained by the contact profiler.

Raman spectroscopic analysis was performed using a Horiba Jobin Yvon Labram Aramis confocal imaging system with a $532 \mathrm{~nm} \mathrm{Nd:YAG} \mathrm{laser} \mathrm{source} \mathrm{(200} \mathrm{mW} \mathrm{power).} \mathrm{A} \mathrm{10x} \mathrm{objective}$ with an optical density filter (OD 0.3) used to limit the laser irradiance on the sample to avoid laser induced crystallization. In addition, the optical image of the sample before and after Raman analysis was examined to ensure that laser irradiance did not affect the sample (if it is affected, the spot under examination would appear discolored).

According to Fujii et al., it was determined that a minimum of $\sim 4.3 \times 10^{6} \mathrm{~mW} / \mathrm{cm}^{2}$ power density is required to crystallize a-Si thin films, which is two orders higher than the laser power used in the Raman spectroscopic analysis in the present studies [15]. In addition, $90 \mathrm{~nm}$ a-Si thin 
films deposited using PECVD studied using Raman spectroscopy under the same condition showed on-set crystallization when a 50x objective with 0.3 OD filter was used. Any laser power below this had no effect on the film that could be detected by Raman Spectra or visual coloration.

Surface topographical details of the films were deduced using a Veeco-DI3100 AFM in tapping mode. The electrical properties of the films were determined using an Agilent B1500A semiconductor analyzer under AM 1.5G illumination (light) and inside a grounded metal shell (dark). Optical bandgap of the silicon films was deduced from optical transmission spectra obtained using a Cary UV-Vis-NIR spectrophotometer according to the method of Tauc [16].

\section{Results and discussions}

\subsection{Growth rate and activation energy}

The growth rate of the Si film depends on several parameters including precursor feed rate, substrate temperature, gas flow rate, system geometry, etc. In this study, substrate temperature and duration of growth were varied, while all other parameters were held constant. After deposition, growth rate was determined from film thickness and duration of growth. The growth rate of the Si thin films obtained from CPS and CHS at $300{ }^{\circ} \mathrm{C}$ to $500{ }^{\circ} \mathrm{C}$ is presented in Fig. 2 , with a literature comparison to $\mathrm{Si}$ thin film growth rate at ambient pressure using $\mathrm{SiH}_{4}$ [17]. It is evident (from Fig. 2) that Si thin films with significant growth rates can be obtained using CPS and CHS at temperatures as low as $300{ }^{\circ} \mathrm{C}$, which is not feasible with $\mathrm{SiH}_{4}$. As a comparison, to obtain a growth rate of $10 \mathrm{~nm} / \mathrm{s}$ using $\mathrm{SiH}_{4}$, a temperature of $900{ }^{\circ} \mathrm{C}$ is necessary, while with CPS and CHS such growth rates can be obtained at $400-500{ }^{\circ} \mathrm{C}$. Within the experimental limits presented here, growth rates up to $45-55 \mathrm{~nm} / \mathrm{s}$ were obtained using CPS and CHS. 


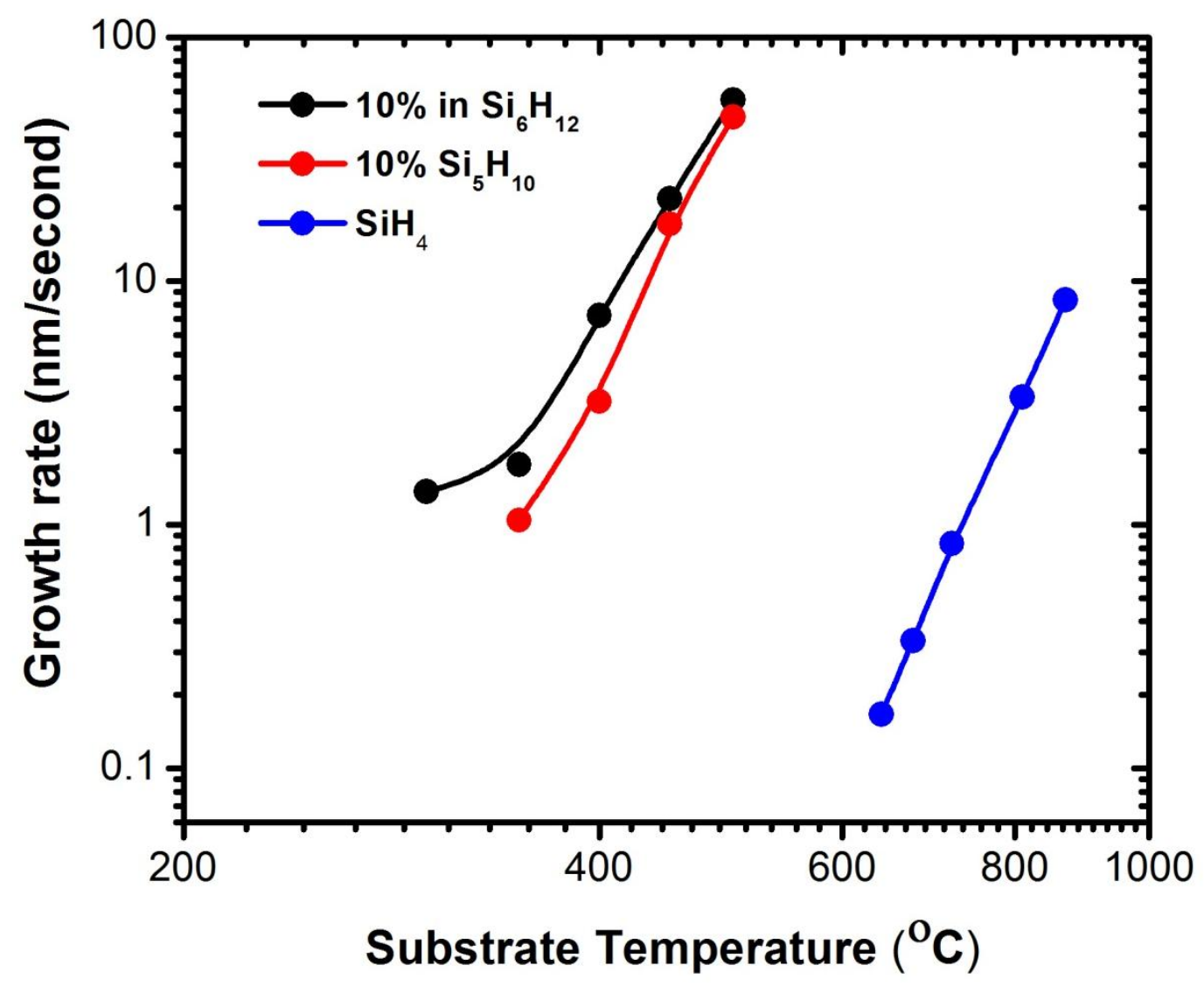

Fig. 2. Growth rate of Si thin films obtained using CPS, CHS and monosilane (data from ref$[17,19])$ at atmospheric pressure.

A detailed literature analysis provides supporting evidence that growth rate is a direct correlation to the order of silane. Kanoh et al., used tri- and tetra- silane in a low-pressure CVD process to obtain Si films at temperatures down to $300{ }^{\circ} \mathrm{C}[7,8]$ while a maximum growth rate of $1.7 \mathrm{~nm} / \mathrm{s}$ was achieved at $500{ }^{\circ} \mathrm{C}$ and $1.2 \times 10^{3}$ Pascal reactor pressure with tetrasilane [8]. Ellis et al., using a mixture of polysilanes with APCVD deposited Si films at a $8.5 \mathrm{~nm} / \mathrm{s}$ growth rate at 525 ${ }^{\circ} \mathrm{C}$ [18]. The growth rates of Si films obtained using CPS and CHS are $~ 28-33$ times higher than that for tetra-silane and $\sim 5.5-6.5$ times higher than that for polysilane precursors. The micro/nano-structure of the Si thin films primarily depends on the substrate temperature and the ad-atom flux. The Si thin films obtained using monosilane (referred above) were crystalline, while all other films obtained from higher order silanes were amorphous, nanocrystalline, or mixtures thereof. A detailed description on microstructural analysis of the Si thin films obtained from CHS is presented below. 
Table-1: Activation energy of various silanes.

\begin{tabular}{|l|l|l|l|}
\hline Silane & $\begin{array}{l}\text { Physical } \\
\text { State } \\
(\text { at STP })\end{array}$ & $\begin{array}{l}E_{\mathrm{a}} \\
(\mathrm{eV})\end{array}$ & Reference \\
\hline $\mathrm{SiH}_{4}$ & Gas & $1.62-2.5$ & {$[17]$} \\
\hline $\mathrm{Si}_{2} \mathrm{H}_{4}$ & Gas & $2.38-3.0$ & {$[8,20,21]$} \\
\hline $\mathrm{Si}_{3} \mathrm{H}_{8}$ & Gas & 1.63 & {$[7]$} \\
\hline $\mathrm{Si}_{4} \mathrm{H}_{10}$ & Liquid & 1.38 & {$[8]$} \\
\hline $\mathrm{Si}_{5} \mathrm{H}_{10}$ & Liquid & 0.34 & this work \\
\hline $\mathrm{Si}_{6} \mathrm{H}_{12}$ & Liquid & 0.30 & this work \\
\hline
\end{tabular}

In CVD, growth characteristics of the films depend on the thermo-chemical properties of the precursor used. The growth activation energy $\left(E_{\mathrm{a}}\right)$ of the given precursor is determined from the slope of film growth rate $v s$. temperature curves. Using the growth rate curves presented in Fig. 2, the $E_{\mathrm{a}}$ of CPS and CHS were determined (using Arrhenius relations [22, 23]) to be 0.35 and $0.3 \mathrm{eV}$, respectively. The $E_{\mathrm{a}}$ of other silanes (gaseous and liquid) are presented in Table-1. In general, precursors with lower $E_{\mathrm{a}}$ form films at lower temperature; CPS and CHS have an lower $E_{\mathrm{a}}$ than other silanes and produce films at lower temperatures. The film growth curves presented in Fig. 2 show little change in the slope in the experimented temperature window, indicating that the growth is still surface reaction controlled, where surface diffusion of ad-atoms prevails [24]. Extending the window to higher temperatures may shed light on when the growth is mass transport limited.

\subsection{Surface morphology}



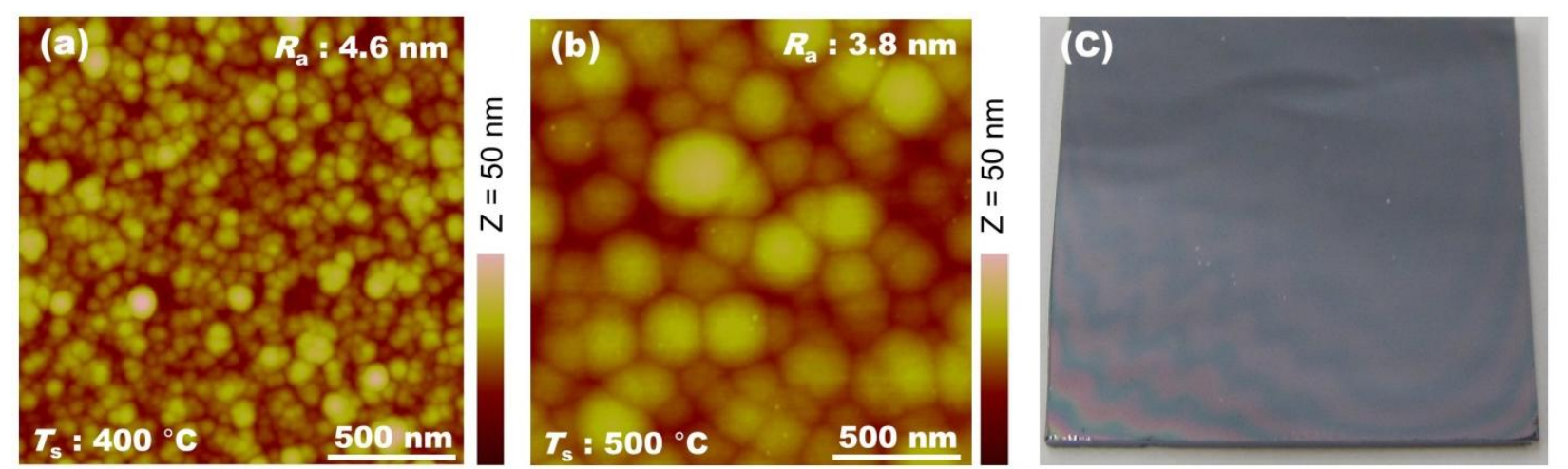

Fig. 3. (a) \& (b) AFM surface topography of Si thin films deposited using AA-APCVD at $400{ }^{\circ} \mathrm{C}$ and $500{ }^{\circ} \mathrm{C}$, respectively; and (c) photograph of Si thin film deposited using AAAPCVD with CHS at $500{ }^{\circ} \mathrm{C}$.

The surface morphology of the Si thin films was measured using AFM. The topographic features of the thin films deposited using CHS at $400{ }^{\circ} \mathrm{C}$ and $500{ }^{\circ} \mathrm{C}$ are shown in Fig. 3(a) and 3(b), respectively. It can be seen that the surface roughness $\left(R_{\mathrm{a}}\right)$ decreased with an increase in deposition temperature. Both roughness values depict an atomically smooth surface with $R_{\mathrm{a}}$ less than $5 \mathrm{~nm}$ akin to films obtained using other CVD processes [25]. The small globule-like features or grains had a mean diameter of $55 \mathrm{~nm}$ for the films deposited at $400{ }^{\circ} \mathrm{C}$, and $167 \mathrm{~nm}$ at $500{ }^{\circ} \mathrm{C}$. The increase in grain size and concomitant decrease in $R_{\mathrm{a}}$ with increased deposition temperature is reported for several thermally activated Si thin films and agrees with our previous report on thermal treatment of spin-coated Si films [10]. Fig 3(c) is a photograph of the Si thin film deposited at $500{ }^{\circ} \mathrm{C}$ with CHS where the film is $\sim 2 \mu \mathrm{m}$ thick.

An increase in substrate temperature enables enhanced fragmentation of silane, allowing for more active molecules on the substrate (for the film growth). This reaction is believed to increase the growth rate with temperature. The adsorbed activated molecules/ad-atoms on the surface acquire additional energy from the increase in substrate temperature to diffuse on the surface to form smooth films [24]. The concomitant decrease in surface roughness with an increase in deposition rate as a function of substrate temperature further indicates film growth mechanism in AA-APCVD with CPS and CHS is surface diffusion controlled in the temperature regime examined in this article [24]. 


\subsection{Raman spectroscopic analysis}

The Si films deposited at various substrate temperatures were characterized using Raman spectroscopy to determine the crystallinity and crystallite size. Fig. 4(a) shows the Raman spectra of the films deposited at different substrate temperatures. Film deposited at $300{ }^{\circ} \mathrm{C}$ exhibits a broad band between 475 to $500 \mathrm{~cm}^{-1}$ arising from the transverse-optical (TO) phonon mode of a-Si [26]. A similar trend was observed for Si thin films deposited at $250{ }^{\circ} \mathrm{C}$ (not shown). As the substrate temperature increases, the band position shifts to higher wavenumbers indicating an ordering in the structure. The presence of a broad band at 490 to $500 \mathrm{~cm}^{-1}$ indicates the existence of intermediate or mixed phases (arising from grain boundaries, defects and ordered small crystallites in the a-Si phases) for the films deposited at $350{ }^{\circ} \mathrm{C}$ and above [27]. The band that appears between 500 and $510 \mathrm{~cm}^{-1}$ is characteristic of nc-Si phase (ordered c-Si peak appears at $521.5 \mathrm{~cm}^{-1}$ ) $[26,28]$. At deposition temperatures of 400 and $450{ }^{\circ} \mathrm{C}$ the contribution from the mixed and nc-Si phases increases showing higher concentrations of nc-Si in the film. For the $\mathrm{Si}$ film deposited at $500{ }^{\circ} \mathrm{C}$, there is a downward shift in the band position indicating the presence of an a-Si:H phase.

To determine the individual contributions arising from the various phases of $\mathrm{Si}$, normalized Raman spectra were de-convoluted into three Gaussian components corresponding to amorphous (440-490 $\left.\mathrm{cm}^{-1}\right)$, intermediate $\left(490-500 \mathrm{~cm}^{-1}\right)$ and crystalline $\left(500-520 \mathrm{~cm}^{-1}\right)$ phases. Fig. 4(b) depicts the de-convoluted spectra of a Si thin film deposited at $450{ }^{\circ} \mathrm{C}$. The crystalline volume fraction present in the films was determined using the relation,

$$
X_{C}=\frac{I_{b}+I_{c}}{\alpha I_{a}+I_{b}+I_{c}},
$$

Where $I_{a}, I_{b}$ and $I_{c}$ are the integrated intensities of the component peaks of a-Si:H, mixed phase and nc-Si phases, respectively; and $\alpha$ is the ratio of the integrated Raman cross-section of the amorphous phase which is practically unity $[26,28]$. Fig. 4(c) shows the change in the $X_{\mathrm{c}}$ with substrate temperature. The Si films deposited at $300{ }^{\circ} \mathrm{C}$ show no crystallite phase, while the films deposited at $350{ }^{\circ} \mathrm{C}$ show $\sim 52.8 \%$ crystalline phase, along with contributions from the mixed phase. Similar features were observed for Si films deposited at 400 and $450{ }^{\circ} \mathrm{C}$, but with a significantly increased contribution from the nc-Si:H phase. Films deposited at $500{ }^{\circ} \mathrm{C}$ show little contribution from the nc- Si:H phase. 
The crystalline volume fraction $\left(X_{\mathrm{c}}\right)$ present in the films was also determined using the method proposed by Smit et al., [29, 30, 31, 32] where the contributions arising from the a-Si phase were removed by subtracting the experimental spectra of Si samples deposited at $(350,400,450$ and $500{ }^{\circ} \mathrm{C}$ ) from the spectra of the sample obtained at $300{ }^{\circ} \mathrm{C}$. In $X_{\mathrm{c}}$ determination, the intermediate phase is also considered as a contributor to the c-Si phase in the sample. The observed $X_{\mathrm{c}} \%$ for samples deposited at $350,400,450$ and $500{ }^{\circ} \mathrm{C}$ are $58.3,78.5,83.4$, and $71.4 \%$, respectively, which is not considerably different from the $X_{\mathrm{c}}$ obtained using the former method.

The average crystallite size, $D$ is determined from the expression;

$$
D=2 \pi\left(\frac{B}{\Delta \omega}\right)^{1 / 2}
$$

where $B$ is a constant $\left(B=2.21 \mathrm{~nm}^{2} . \mathrm{cm}^{-1}\right)$ and $\Delta \omega$ is the peak shift from the c-Si peak $\left(521.5 \mathrm{~cm}^{-}\right.$ $\left.{ }^{1}\right)[26,28,33]$. Using the above relation the crystallite size of the films deposited at 400, 450 and $500{ }^{\circ} \mathrm{C}$ were determined to be $1.8,2.0$ and $2.5 \mathrm{~nm}$, respectively.

An increase in substrate temperature causes a change in the microstructure of the deposited $\mathrm{Si}$ thin films. Films deposited at 250 and $350{ }^{\circ} \mathrm{C}$ consist predominantly of a-Si:H, while films deposited at 400 and $450{ }^{\circ} \mathrm{C}$ contain a significant fraction of the nc-Si:H phase, co-existing with mixed and a-Si:H phases. Films deposited at $500{ }^{\circ} \mathrm{C}$, show a decrease in the nc-Si:H and increase in the a-Si:H phases. The concentration of CHS reaching the substrate rapidly increases with substrate temperature as explained above and enhances the film growth rate, but the silane molecule that reaches the substrate does not undergo complete disassociation (compared with films deposited at low temperatures). This limited disassociation could lead to films that are less dense and hence inferior in quality. 

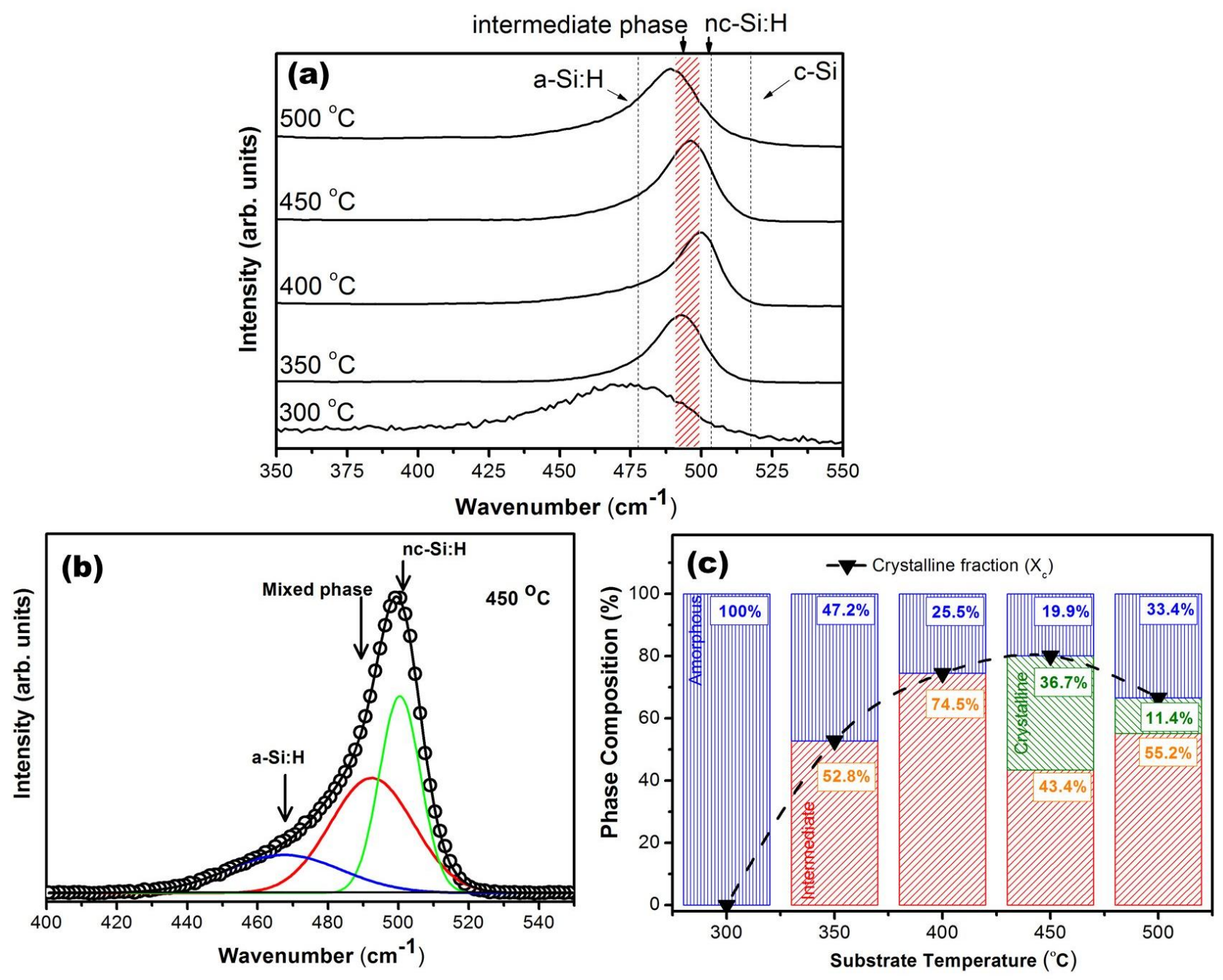

Fig. 4. Raman spectroscopic analysis of (a) change in the spectral features with increase in substrate temperature [19] (b) De-convoluted Raman spectra of a Si thin film deposited at $450{ }^{\circ} \mathrm{C}$ and (c) contribution of $\mathrm{Si}$ phases and crystalline volume fraction with substrate temperature.

\subsection{Optical properties}

The optical bandgap of the Si thin films were deduced from the UV-Vis transmission spectra using Tauc's method where the relation for an indirect bandgap semiconductor is given by;

$$
(\alpha h v)^{\frac{1}{2}}=K\left(E-E_{g}\right),
$$


where $\alpha$ is the absorption coefficient, $K$ is the joint optical density of states, $E$ is the photon energy, and $E_{g}$ is the optical bandgap[16]. Tauc's plot of Si thin films obtained using UV-Vis transmission spectra and the bandgap of Si films are presented in Fig. 5. The wide bandgap $\left(E_{g}\right.$ $=2-2.28 \mathrm{eV}$ ) determined for the films deposited at $350{ }^{\circ} \mathrm{C}$ and $400{ }^{\circ} \mathrm{C}$, illustrates characteristics of a-Si:H [34, 35], while the value of $\sim 1.7-1.8 \mathrm{eV}$ for films deposited at $450{ }^{\circ} \mathrm{C}$ and $500{ }^{\circ} \mathrm{C}$ reveals the presence of nc-Si:H $[36,37]$.

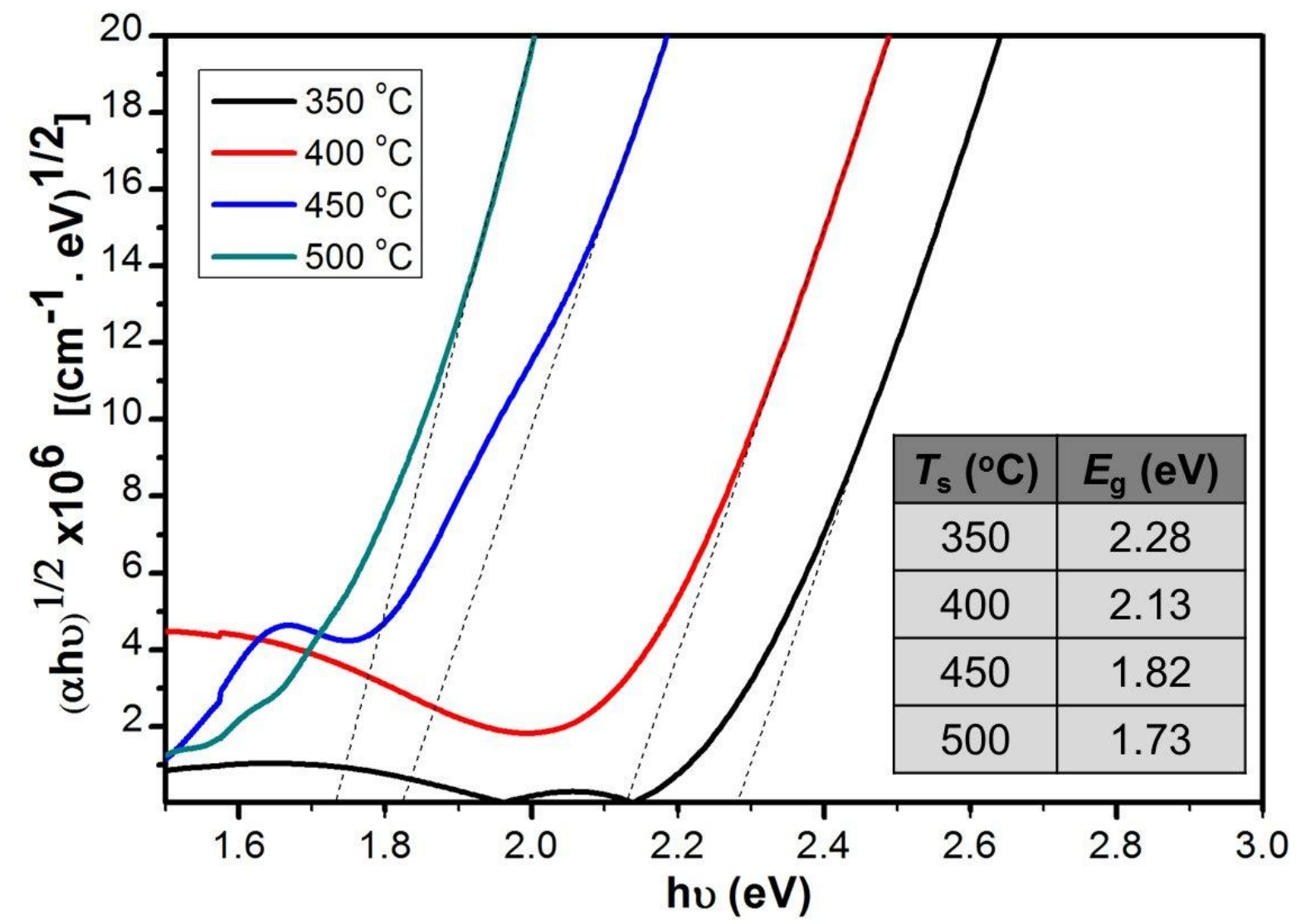

Fig.5. Tauc's plot obtained from UV-Vis transmission spectra (inset: change in $E_{\mathrm{g}}$ with temperature).

The bandgap of $\mathrm{Si}$ and $\mathrm{H}$ containing thin films depends on the hydrogen concentration and crystalline content. In this case, the reduction in bandgap with increasing temperature may be attributed to a decrease in the hydrogen content and increase in crystallinity in the film with substrate temperature. Generally a-Si:H films have an $E_{\mathrm{g}}$ higher than $1.8 \mathrm{eV}$, while nanocrystalline $\mathrm{Si}$ thin films have an $E_{\mathrm{g}}$ between 1.5-1.8 eV [34-37]. The bandgap of $\mathrm{Si}$ decreases with an increase in the order; microcrystalline silicon $(\mu \mathrm{c}-\mathrm{Si}: \mathrm{H})$ thin films and bulk 
single crystalline (c- $\mathrm{Si}$ ) have a bandgap of $1.2-1.5 \mathrm{eV}$ and $1.1 \mathrm{eV}$, respectively [38]. Raman spectroscopic analyses of the obtained Si thin films show an amorphous to nanocrystalline transformation with an increase in temperature consistent with the observed change in the bandgap. In thermal CVD processes, the structure of the Si thin film depends on the desorption of hydrogen and the flux of the precursor molecule reaching the film growing surface. Whereas in PECVD, hydrogen content in the plasma and plasma parameters influences the growth of $\mathrm{Si}$ thin films [39]. A decrease in the $E_{\mathrm{g}}$ with an increase in the substrate temperature was previously reported and our results follow the similar trend [7].

\subsection{Electrical Properties of Si thin films}

The electrical properties of Si thin films play a significant role in the performance properties of solar cells and microelectronic devices. In semiconducting thin film devices, the photogenerated carriers are extracted to their respective electrodes by establishing an internal field. Photosensitivity factors (defined as the ratio of light to dark conductivity) $\geq 10^{5}$ represent a device/photovoltaic quality Si film. The dark and light conductivity of Si thin films deposited with CHS at different temperatures is presented in Fig. 6. The Si films deposited at 350 and 400 ${ }^{\circ} \mathrm{C}$ with dark conductivity of $10^{-11}$ to $10^{-10} \mathrm{~S} / \mathrm{cm}$ and a light conductivity value of $10^{-8} \mathrm{~S} / \mathrm{cm}$ (photosensitivity of $10^{2}-10^{3}$ ) represent a near-device quality $\mathrm{Si}$ thin film. A quality $\mathrm{Si}$ thin film exhibits a dark conductivity of $10^{-11} \mathrm{~S} / \mathrm{cm}$ (indicates the absence of electrically active defects); and a light conductivity of $10^{-5} \mathrm{~S} / \mathrm{cm}$ (represents a low recombination of charge carriers in the film) $[3,40,41]$. The dark conductivity of $10^{-11} \mathrm{~S} / \mathrm{cm}$ observed for these Si thin films with CHS represents the presence of a minimum amount of electrically active defects in the films and in the starting material (CHS) in the form of contaminants. On the other hand, the decrease in the light conductivity (compared with standard Si films) can be assumed to arise from the dangling bond defects that are common in hydrogenated Si thin films [10]. Introduction of hydrogen radicals during the deposition, or post-deposition H-radical treatment, can chemically anneal these defects and improve the photosensitivity of these Si thin films [39].

\subsection{Growth model}

Si thin film growth of mono and disilanes via CVD are well studied [6, 42, 43]. Gas-phase decomposition of the precursor to form active radicals, reaction between these radicals, its 
adsorption on the substrate surface, and its subsequent chemical reactions, nucleation and thin film growth occur in sequence. Some of the important reactions that occur in the gas-phase and on the substrate leading to film growth are summarized in schemes 1-6. Gas-phase thermal decomposition of mono and disilane produces $\mathrm{Si}_{2} \mathrm{H}_{4}$ moieties (schemes 1, 2 and 3). These moieties upon adsorption to the substrate undergo hydrogen elimination reactions (schemes 4, 5 and 6) to form Si thin films. Using disilane as the precursor is beneficial when compared to $\mathrm{SiH}_{4}$ because it can form disilene $\left(\mathrm{H}_{2} \mathrm{SiSiH}_{2}\right)$ via hydrogen elimination and silylsilylene $\left(\mathrm{H}_{3} \mathrm{SiSiH}\right)$ through isomerization of the disilene. Tri- and tetrasilane decompose thermally to produce similar species at reduced temperatures, compared to lower order silanes [3-8].

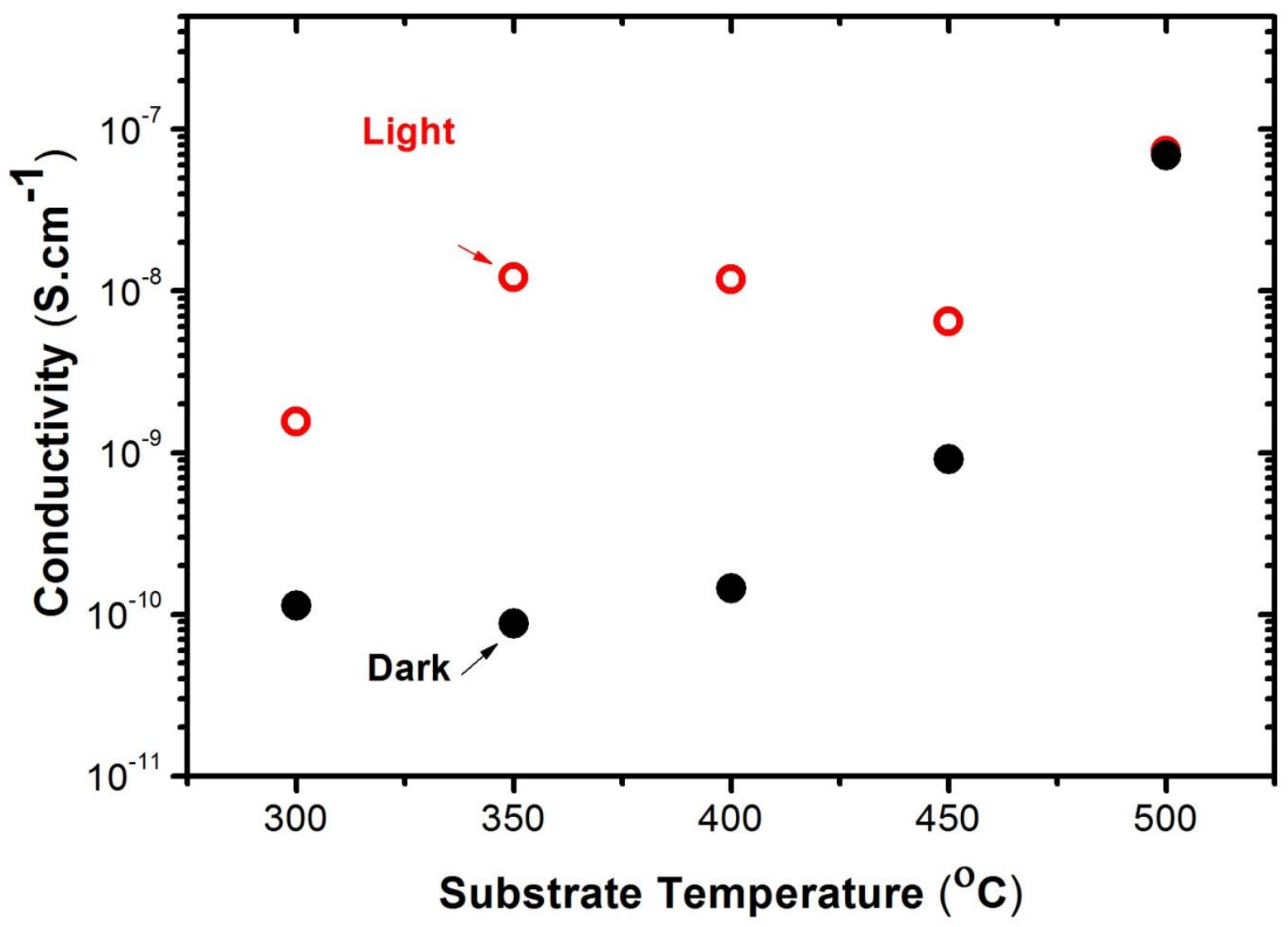

Fig. 6. Dark and light conductivity of Si thin films deposited using CHS via aerosol assisted AA-APCVD [19].

$\mathrm{SiH}_{4}(*) \longrightarrow \mathrm{SiH}_{2}(*)+\mathrm{H}_{2} \uparrow$

$\mathrm{SiH}_{2}(*)+\mathrm{SiH}_{4}(*) \longrightarrow \mathrm{Si}_{2} \mathrm{H}_{6}(*)$

$\mathrm{Si}_{2} \mathrm{H}_{6}(*) \longrightarrow \mathrm{SiH}_{2}-\mathrm{SiH}_{2}(*)+\mathrm{H}_{2} \uparrow$ 
$\mathrm{SiH}_{2}-\mathrm{SiH}_{2}(*) \longrightarrow \mathrm{SiH}-\mathrm{SiH}(\#)+\mathrm{H}_{2} \uparrow$

$\mathrm{SiH}_{2}+\mathrm{SiH}_{2}(*) \longrightarrow \mathrm{SiH}-\mathrm{SiH}(\#)+\mathrm{H}_{2} \uparrow$

$\mathrm{SiH}-\mathrm{SiH}(\#) \longrightarrow 2 \mathrm{Si}(\#)+\mathrm{H}_{2} \uparrow$

*- Gas-phase reactions; \#-reaction occurring on the substrate

From the observed experimental results (AA-APCVD) we propose that the thermal decomposition of CHS occurs via ring opening in the gas-phase leading to complex silane chemistries that likely include dihydrosilylene $\left(\mathrm{SiH}_{2}\right)$, linear oligosilylsilylenes $\left(\mathrm{H}_{3} \mathrm{Si}\left(\mathrm{SiH}_{2}\right)_{\mathrm{n}} \mathrm{SiH}\right)$, linear oligosilenes $\left(\mathrm{H}_{3} \mathrm{Si}\left(\mathrm{SiH}_{2}\right)_{\mathrm{n}} \mathrm{SiHSiH}_{2}\right)$, cyclic oligosilylsilylenes $\left(\left(\mathrm{SiH}_{2}\right)_{\mathrm{n}} \mathrm{Si}\right)$ and cyclic oligosilenes $\left(\left(\mathrm{SiH}_{2}\right)_{\mathrm{n}}(\mathrm{SiH})_{2}\right)$ (schemes 7, 8 and 9). These complex, high molecular weight oligosilylsilylenes and oligosilenes attach to the open sites on the substrate and undergo surface reactions to form Si thin films (schemes 10, 11 and 12). Compared to mono, di, tri and tetrasilanes, cyclic silanes require less activation energy $(<0.35 \mathrm{eV})$ to form reactive oligosilenes and oligosilylsilylenes, which have a high probability of adsorption on the substrate.

$$
\begin{aligned}
& n\left[\mathrm{Si}_{6} \mathrm{H}_{12}\right](*) \longrightarrow\left[\mathrm{SiH}_{2}\right]_{6 n}(*) \\
& n\left[\mathrm{Si}_{6} \mathrm{H}_{12}\right](*) \longrightarrow 6 n\left[\mathrm{SiH}_{2}\right](*) \\
& n\left[\mathrm{Si}_{6} \mathrm{H}_{12}\right](*) \longrightarrow n\left[\left(\mathrm{SiH}_{2}\right)_{4}(\mathrm{SiH})_{2}\right](*)+\left(\frac{n}{2}\right) \mathrm{H}_{2} \uparrow(9) \\
& n\left[\mathrm{SiH}_{2}\right](*) \longrightarrow[\mathrm{SiH}]_{n}(\#)+\left(\frac{n}{2}\right) \mathrm{H}_{2} \uparrow \\
& {\left[\mathrm{SiH}_{2}\right]_{n}(*) \longrightarrow[\mathrm{SiH}]_{n}(\#)+\left(\frac{n}{2}\right) \mathrm{H}_{2} \uparrow} \\
& n[\mathrm{SiH}-\mathrm{SiH}](\#) \longrightarrow 2 n S i(\#)+\mathrm{H}_{2} \uparrow
\end{aligned}
$$

Hydrogen concentration and the fraction of $\mathrm{Si}-\mathrm{H}, \mathrm{Si}-\mathrm{H}_{2}, \mathrm{Si}-\mathrm{H}_{3}$ and $\mathrm{Si}-\mathrm{Si}$ bonds determine the microstructure and properties of $\mathrm{Si}$ thin films. Hydrogenated $\mathrm{Si}$ thin films with suitable properties can be obtained by controlling precursor flux and substrate temperature. In this investigation, the flow-rate of CHS was maintained constant. Si thin films deposited at higher temperatures show significant fractions of crystallinity and a decline in photosensitivity compared to low temperature Si films. Molecules arriving at the heated substrate undergo 
fragmentation to form a more ordered $\mathrm{Si}-\mathrm{H}$ network (nc-Si:H), but the flux is high and efficient fragmentation is suppressed leading to the growth of a mixture of a-Si/c-Si phases. Highly ordered films with device quality are generally obtained with reduced deposition rates compared to a-Si films [2]. Though the addition of $\mathrm{H}_{2}$ has little effect in AA-APCVD (in our temperature regime), introduction of hydrogen radicals (H-plasma) on Si:H thin films can passivate the dangling bonds and anneal defects to improve electronic properties $[44,45]$.

Similarly, using liquid silane with nitrogen containing reactive gases with or without plasma, realized good quality $\mathrm{SiN}_{\mathrm{x}}$ thin films at temperatures below $500{ }^{\circ} \mathrm{C}$ [46]. We also observed that in AA-APCVD more than $40 \%$ of silane is converted into a Si thin film, which is greater than state-of-the-art PECVD Si deposition. Presently, liquid silanes are more expensive than gaseous silanes; scaled production is expected to yield better quality liquid silanes more efficiently than currently technology [46]. Thus, the combinations of liquid silanes and processing with AAAPCVD has the potential to lower cost of manufacturing Si based thin film devices.

\section{Conclusions}

Si thin films were deposited via AA-APCVD using the liquid silanes cyclopentasilane (CPS) and cyclohexasilane (CHS). The effects of substrate temperature on the growth rate, surface morphology, microstructure, and electrical properties were investigated. A growth rate of 47 and $55 \mathrm{~nm} / \mathrm{s}$ were obtained at $500{ }^{\circ} \mathrm{C}$ using CPS and CHS respectively. Higher growth rates of $\mathrm{Si}$ thin films are attributed to the lower activation energies of these silanes. Films deposited at or below $300{ }^{\circ} \mathrm{C}$ were amorphous, while films deposited between $350-500{ }^{\circ} \mathrm{C}$ consisted of nanocrystalline and intermediate phases in addition to an amorphous phase. Raman spectroscopic analysis suggests that, by controlling the precursor feed-rate and substrate temperature, it might be possible to control the microstructure of the thin film. Near device quality (photosensitivity of $10^{2}-10^{3)} \mathrm{Si}$ films were realized at 350 and $400{ }^{\circ} \mathrm{C}$. Thus thin film deposition using liquid silanes at ambient pressure may enable continuous roll-to-roll manufacturing of $\mathrm{Si}$ thin films and devices. 


\section{Acknowledgement}

The financial support from the Department of Energy (Grant DE-FC36-08G088160) is gratefully acknowledged. The views and conclusions contained herein are those of the authors and should not be interpreted as necessarily representing the official policies or endorsements, either expressed or implied of the Department of Energy or the U. S. Government. The authors wish to acknowledge Dr. Heidi Docktor, Mr. Gregory Strommen, Mr. Kevin Mattson and Mr. Matthew Semler for technical assistance. 


\section{References}

[1] M. A. Kreiger, D. R. Shonnard, J. M. Pearce, Life cycle analysis of silane recycling in amorphous silicon-based solar photovoltaic manufacturing, Resour. Conserv. Recy., 70 (2013) 44-49.

[2] C. A. Wolden, J. Kurtin, J. B. Baxter, I. Repins, S. E. Shaheen, J. T. Torvik, A. A. Rockett, V. M. Fthenakis, E. S. Aydil, Photovoltaic manufacturing: Present status, future prospects, and research needs, J. Vac. Sci. Technol. A, 29 (2011) 030801.

[3] K. H. Chung, J. C. Sturm, E. Sanchez, K. K. Singh, and S. Kuppurao, The high growth rate of epitaxial silicon-carbon alloys by using chemical vapour deposition and neopentasilane, Semicond. Sci. Technol. 22 (2007) S158-S160.

[4] K. H. Chung, N. Yao, J. Benziger, J. C. Sturm, K. K. Singh, D. Carlson, S. Kuppurao, Ultrahigh growth rate of epitaxial silicon by chemical vapor deposition at low temperature with neopentasilane, Appl. Phys. Lett. 92 (2008) 113506.

[5] W. A. Eger, A. Genest, and N. Rösch, Thermal Decomposition of Branched Silanes: A Computational Study on Mechanisms, Chem. Eur. J., 18 (2012) 9106-9116.

[6] S.-W. Hu, Y. Wang, X.-Y. Wang, T.-W. Chu, X.-Q. Liu, Gas-Phase Reaction Pathways from $\mathrm{SiH}_{4}$ to $\mathrm{Si}_{2} \mathrm{H}_{6}, \mathrm{Si}_{2} \mathrm{H}_{4}$ and $\mathrm{Si}_{2} \mathrm{H}_{2}: \square$ A Theoretical Study, J Phys. Chem. A, 107 (2003) 2954-2963.

[7] H. Kanoh, O. Sugiura, P. A. Breddels, M. Matsumura, Optimization of Chemical VaporDeposition Conditions of Amorphous-Silicon Films for Thin-Film Transistor Application, Jap. J. Appl. Phys. Part-1, 29 (1990) 2358-2364.

[8] H. Kanoh, O. Sugiura, M. Matsumura, Chemical-Vapor-Deposition of AmorphousSilicon Using Tetrasilane, Jap. J. Appl. Phys. Part-132 (1993) 2613-2619.

[9] K. H. Chung, Silicon based epitaxy by chemical vapor deposition using novel precursor neopentasilane, PhD-thesis, Princeton University, 2010.

[10] G. R. S. Iyer, E. K. Hobbie, S. Guruvenket, J. M. Hoey, K. J. Anderson, J. Lovaasen,, A. Elangovan and P. J. Boudjouk, Solution-Based Synthesis of Crystalline Silicon from Liquid Silane through Laser and Chemical Annealing, ACS Appl. Mater. Inter., 4 (2012) 2680-2685. 
[11] S. Tatsuya M. Takashi, Liquid silicon and its application in electronics, Jap. J. Appl. Phys., 53(2014) 02BA01.

[12] S. B. Choi, B. K. Kim, P. Boudjouk, D. G. Grier, Amine-promoted disproportionation and redistribution of trichlorosilane: Formation of tetradecachlorocyclohexasilane dianion, J. Am. Chem. Soc., 123 (2001) 8117-8118.

[13] A. Elangovan, K. Anderson, P. R. Boudjouk, D. L. Schulz, Method of producing cyclohexasilane compounds, WO 2011094191 A1, 2011.

[14] W. Kern, The Evolution of Silicon-Wafer Cleaning Technology, J. Electrochem. Soc. 137 (1990) 1887-1892.

[15] S. Fujii, S. Kuroki, X. Zhu, M. Numata, K. Kotani and T. Ito, Analysis of ContiniousWave Laser Lateral Crytallized Polycrystalline Silicon Thin Films with Large Tensile Strain, Jap. J. Appl. Phys., 47 (2008) 3046-3049.

[16] J. Tauc and A. Menth, States in the gap, J. Non-Cryst. Sol. 8-10 (1972) 569-585.

[17] Eversteyn. C, Chemical-Reaction Engineering in Semiconductor Industry, Philips Res. Rep., 29 (1974) 45-66.

[18] F. B. Ellis, R. G. Gordon, Simple Method for Preparing Hydrogenated AmorphousSilicon Films by Chemical Vapor-Deposition at Atmospheric-Pressure, J. Appl. Phys., 54, (1983) 5381-5384.

[19] S. Guruvenket, K. J. Anderson, M. Frohlich, G. Strommen, R. A. Sailer, P. J. Boudjouk, Atmospheric Pressure Chemical Vapor Deposition of Silicon thin films using Cyclehexasilane, Photovoltaic Specialists Conference (PVSC), 2014, 40 ${ }^{\text {th }}$ IEEE, (2014) 3068-3070.

[20] T. L. Chu, S. S. Chu, S. T. Ang, D. H. Lo, A. Duong, C. G. Hwang, Deposition and photoconductivity of hydrogenated amorphous silicon films by the pyrolysis of disilane, J. Appl. Phys. 59 (1986) 1319-1322.

[21] T. L. Chu, S. S. Chu, S. T. Ang, A. Duong, Y. X. Han, Y. H. Liu, Hydrogenated amorphous silicon films deposited in a helium atmosphere, J Appl. Phys. 60 (1986) 42684272.

[22] S. Guruvenket, S. Andrie, M. Simon, K. W. Johnson, R. A. Sailer, Atmospheric-Pressure Plasma-Enhanced Chemical Vapor Deposition of a-SiCN:H Films: Role of Precursors on the Film Growth and Properties, ACS Appl. Mater. Inter., 4 (2012) 5293-5299. 
[23] S. Guruvenket, S. Andrie, M. Simon, K. W. Johnson, R. A. Sailer, Atmospheric Pressure Plasma CVD of Amorphous Hydrogenated Silicon Carbonitride (a-SiCN:H) Films Using Triethylsilane and Nitrogen, Plasma Process. Polym. 8 (2011) 1126-1136.

[24] M. Ohring, Materials Science of Thin Films: Elsevier Science, 2001.

[25] V. S. Waman, A. M. Funde, M. M. Kamble, M. R. Pramod, R. R. Hawaldar, D. P. Amalnerkar, V. G. Sethe, S. W. Gosavi, S. R. Ladkar, Hydrogenated Nanocrystalline Silicon Thin Films Prepared by Hot-Wire Method with Varied Process Pressure, J. Nanotechnol., 2011 (2011) 242398.

[26] Z. Li, W. Li, Y. Jiang, H. Cai, Y. Gong, J. He, Raman characterization of the structural evolution in amorphous and partially nanocrystalline hydrogenated silicon thin films prepared by PECVD, J. Raman Spectros. 42 (2011) 415-421.

[27] S. Huet, G. Viera, L. Boufendi, Effect of small crystal size and surface temperature on the Raman spectra of amorphous and nanostructured $\mathrm{Si}$ thin films deposited by radiofrequency plasmas, Thin Solid Films, 403-404 (2002) 193-196.

[28] R. Tsu, J. Gonzalez Hernandez, S. S. Chao, S. C. Lee, K. Tanaka, Critical volume fraction of crystallinity for conductivity percolation in phosphorus doped $\mathrm{Si}: \mathrm{F}: \mathrm{H}$ alloys, Appl. Phys. Lett., 40 (1982) 534-535.

[29] C. Smit, R. A. C. M. M. van Swaaij, H. Donker, A.M.H. N. Petit, W. M. Kessels, M. C. M. van de Sanden, Determining the material structure of microcrystalline silicon from Raman spectra, J. Appl. Phys. 94 (2003) 3582-3588.

[30] A. Gajovic, D. Gracin, K. Juraic, J Sancho-Parramon, M. Ceh, Correlating Ramanspectroscopy and high resoultion transmission electron microscopy studies of amrophous/nanocrystalline multilayered silicon thin films, Thin Solid Films, 517 (2009) 5433-5458.

[31] A. Le Donne, S. Binetti, G. Isella and S. Pizzini, Structural Homogeneity of nc-Si Films Grown by Low- Energy PECVD, Electrochem. Sol. State. Lett., 11(2008) 5-7.

[32] E. V. Johnson, L. Kroely, and P. R. i. Cabarrocas, Raman Scattering Analysis of SiH bond Streching modes in hydrogenated microcrystalline Silicon for Use in Thin-Film Photovoltaics, Sol. Eng. Mater. Sol. Cells, 93 (2009) 1904-1906.

[33] J. Meier, R. Flückiger, H. Keppner, A. Shah, Complete microcrystalline p-i-n solar cellCrystalline or amorphous cell behavior?, Appl. Phys. Lett., 65 (1994) 860-862. 
[34] W. Futako, K. Yoshino, C. M. Fortmann, I. Shimizu, Wide band gap amorphous silicon thin films prepared by chemical annealing, J. Appl. Phys. 85 (1999) 812-818.

[35] A. Hadjadj, A. Beorchia, P. R. I. Cabarrocas, L. Boufendi, S. Huet, J. L. Bubendorff, Effects of the substrate temperature on the growth and properties of hydrogenated nanostructured silicon thin films, J. Phys. D 34 (2001) 690.

[36] G. B. Tong, Z. Aspanut, M. R. Muhamad, S. Abdul Rahman, Optical properties and crystallinity of hydrogenated nanocrystalline silicon (nc-Si:H) thin films deposited by rfPECVD, Vacuum, 86 (2012) 1195-1202.

[37] D. Das, K. Bhattacharya, Characterization of the Si:H network during transformation from amorphous to micro- and nanocrystalline structures, J. Appl. Phys., 100 (2006) 103701.

[38] D. Han, G. Yue, J. D. Lorentzen, J. Lin, H. Habuchi, Q. Wang, Optical and electronic properties of microcrystalline silicon as a function of microcrystallinity, J Appl. Phys., 87 (2000)1882-1888.

[39] H. Shirai, J. Hanna, I. Shimizu, Role of Atomic-Hydrogen during Growth of Hydrogenated Amorphous-Silicon in the Chemical Annealing, Jap. J. Appl. Phys. Part-2 30 (1991) L679-L682.

[40] J. Ramanujam, A. Verma, Photovoltaic Properties of a-Si:H Films Grown by Plasma Enhanced Chemical Vapor Deposition: A Review, Mater. Exp., 2 (2012) 177-196.

[41] P. Torres, J. Meier, R. Fluckiger, U. Kroll, J. A. A. Selvan, H. Keppner, A. Shah, S. D. Littlewood, I. E. Kelly, P. Giannoules, Device grade microcrystalline silicon owing to reduced oxygen contamination, Appl. Phys. Lett. 69 (1996) 1373-1375.

[42] C. J. Giunta, R. J. Mccurdy, J. D. Chapplesokol, R. G. Gordon, Gas-Phase Kinetics in the Atmospheric-Pressure Chemical Vapor-Deposition of Silicon from Silane and Disilane, J. Appl. Phys., 67 (1990)1062-1075.

[43] K. Tonokura, M. Koshi, Reaction kinetics in silicon chemical vapor deposition, Curr. Opin. Solid State Mater. Sci., 6 (2002) 479-485.

[44] S. Sriraman, S. Agarwal, E. S. Aydil, D. Maroudas, Mechanism of hydrogen-induced crystallization of amorphous silicon, Nature, 418 (2002) 62-65. 
[45] P. Dutta, S. Paul, D. Galipeau, V. Bommisetty, Effect of hydrogen plasma treatment on the surface morphology, microstructure and electronic transport properties of nc-Si:H, Thin Solid Films, 518 (2010) 6811-6817.

[46] S. Guruvenket, R. Sailer and J. Hoey, Synthesis of silicon containing materials using liquid hydrosilane compositions through direct injection, (PCT/US2014/029451), WO2014144862 A2, 2014. 